\title{
Experimental and Simulant Study on the Ground Source Heat Pump in Winter of Hefei
}

\author{
Huizeng $\mathrm{Li}^{1,2}$, Ning $\mathrm{Hu}^{1,3}$, Chongda Jiang ${ }^{1,2}$, Zhengling $\mathrm{Hu}^{1,3}$, Jinwei $\mathrm{Ma}^{1,3}$ and \\ Yanping Wang ${ }^{1,3, a}$
}
1. Anhui Advanced Technology Research Institute of Green Building, Anhui Jianzhu University, Hefei 230601, China;

2. Chinese Hefei Railway Constrction Real Estate Group C.O.. Ltd, Hefei 230041, China;

3. College of Environment and Energy Engineering, Anhui Jianzhu University, Hefei 230601, China.

aEmail:267284143@qq.com

Keywords: ground source, heat pump,u-shaped, heat exchanger

Abstract: Based on the operation of a Ground Source Heat Pump (GSHP) in Hefei, the heat exchange of the $100 \mathrm{~m}$ depth vertical $\mathrm{u}$-shaped pipe buried in the ground was analyzed, and the heat transfer performance, efficiency of the system and temperature variation of the ground were studied experimentally under the typical climate in Hefei. Temperature changes of the field near the heat exchanger after $8 \mathrm{~h}$ and $24 \mathrm{~h}$ were analyzed by numerical simulation. Results show that the system has a good performance in winter.

\section{Introduction}

Ground Source Heat Pump (GSHP) is a kind of air conditioner that can running both in heating and cooling modes through exchanging heat with the ground. The heat exchanger was buried in the ground. This article investigates the performance of the underground heat exchanger and the temperature field around the heat exchanger under the different operating modes of the system. As the high performance of the ground source heat pump system, more and more attention was paid on it. Parham Eslami-Nejad et al. developed a theoretical quasi-transient model for detailed simulations of a carbon di-oxide $\left(\mathrm{CO}_{2}\right)$ direct-expansion ground source heat pump (DX-GSHP)[1]. Hu et al. used extremum seeking control to analyze the efficient operation of hybrid ground source heat pump system[2]. Lyman et al. performed experimental studies on different louver models with varied fin pitch and louver angles over a range of Reynolds numbers. A method for evaluating spatially resolved louver heat transfer coefficients was presented[3]. Weijuan and Pingfang presenteda method to predict the coefficient of performance (COP) of the heat pump and the COPs of ground source heat pump (GSHP) system with limited parameters. The method was based on an artificial neural network (ANN) model and an adaptive neuro-fuzzy inference system (ANFIS) model[4]. The performance of a ground source heat pump (GSHP) system with horizontal coupled ground loop pipes was extrapolated and numerically simulated by Amir A. Safa[5]. Liu et al. made use of TRNSYS, one kind of energy simulation software, to simulate the operation performances of GSHP on basis of these parameters. The simulation revealed the data on the outlet/inlet temperature of buried pipes, soil temperature, energy consumption distribution and the coefficient of performance (COP) for one year operation. These results could be used as a reference on suitable utilization of GSHP systems in office buildings located in cold climate zone of China[6]. Erhan et al. 
evaluated the performance of horizontal GSHP by considering various system parameters for winter climatic condition of Bursa, Turkey, and the results showed that the GSHP system was more cost effective than the all other conventional heating systems [7].

\section{Project profile}

The total construction area of the project is $3339 \mathrm{~m}^{2}$, with a total of four layers, one floor of $908 \mathrm{~m}^{2}$ under the ground and three floors of $2431 \mathrm{~m}^{2}$ above the ground. Cooling load of the air conditioner is $420 \mathrm{~kW}$, and heat load is $380 \mathrm{~kW}$. Ground Source Heat Pump is adapted, fan-coil unit plus fresh air system is chosen as the terminal device.

\section{Experimental research and analysis}

There is unsteady-state heat transfer process between the buried tube and the backfilled material, when heat pump units continuously running, the heat was absorbed or released by the soil constantly, so temperature of the soil was changing. The soil temperature changes greatly with the system running continuously, so the performance of the heat exchanger declines and performance coefficient of the heat pump decreases. The project in this paper belongs to office building, so operation of the system is non-continuously. It is helpful to the thermal balance of underground soil, and it is beneficial to the operation performance of unit and long-term stable operation of the system.

Experiments were carried out during in December 2014 and January 2015.Location of the buried pipes is shown in Fig. 1.It contains 84 heat transfer boreholes with depth of 100 meters totally. It covers an area of about $1300 \mathrm{~m}^{2}$, with a space of 4 meters between each two boreholes. Double U $\mathrm{PE}$ pipe with diameter of $25 \mathrm{~mm}$ was chosen as the heat transfer exchanger. Diameter of the boreholes is $150 \mathrm{~mm}$ and the backfilled material is fine sand. As shown in Fig. 1, K1 and K41 are the test wells. Schematic diagram of the experimental system is shown in Fig. 2.

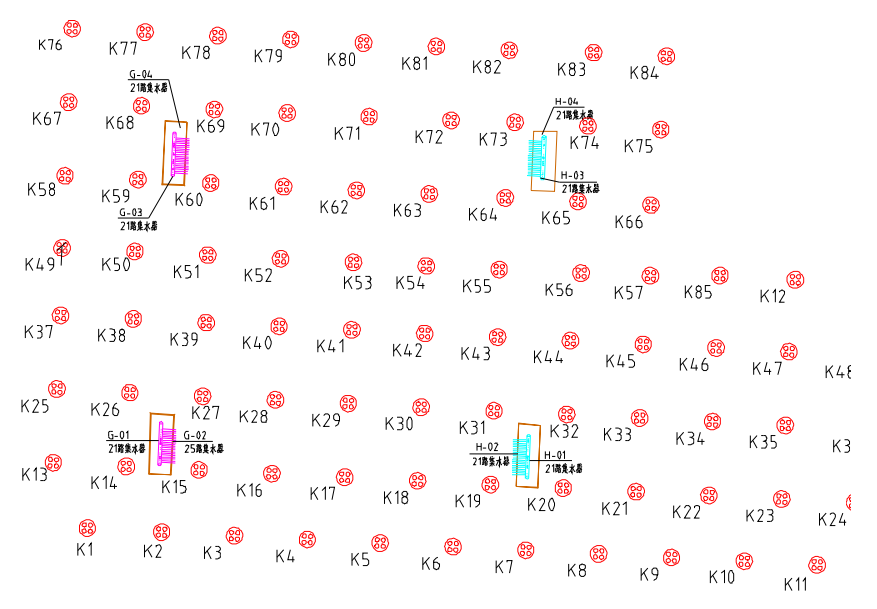

Figure 1 Relative locations of the heat exchanger

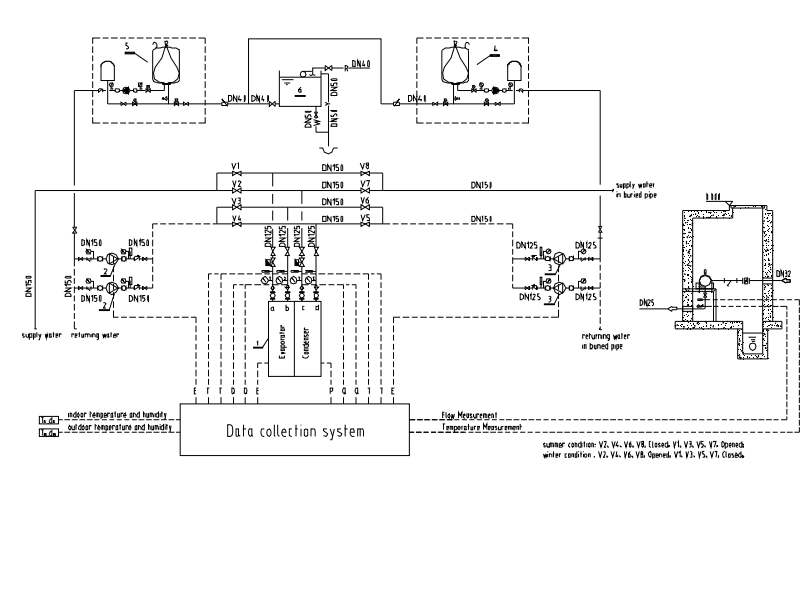

Figure 2 The principle diagram of the experimental system 


\section{The original test at low temperature}

The ground temperature was tested during the period of January 25 to 28 after the experiment system was built. The test data of underground points is shown in Fig.3.

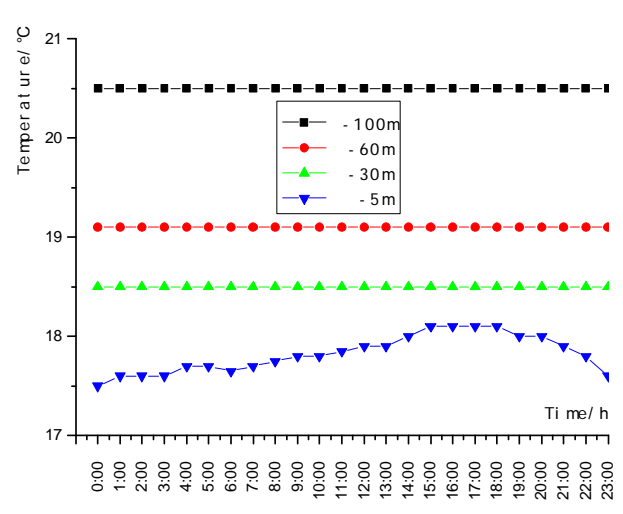

Figure 3 Underground temperature distribution of different depth on $28^{\text {th }}$ January

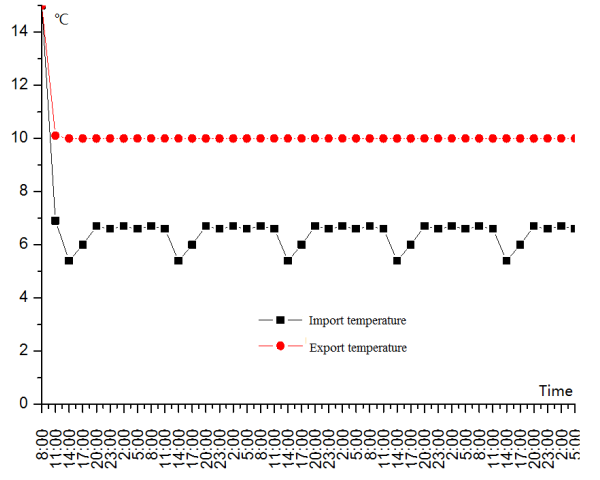

Figure 4 Temperature of import and export of the heat exchanger

According to the Fig. 3, it can be seen that the temperature become higher with the depth of test point increased, meanwhile the change ranges with time decreased.

\section{Continuous working condition of heat removal test}

Continuous operation test was carried out from6 to 12 in January. Water velocity in the pipe buried underground is $0.3 \mathrm{~m} / \mathrm{s}$. Test result is shown in Fig.4 and Fig. 5.

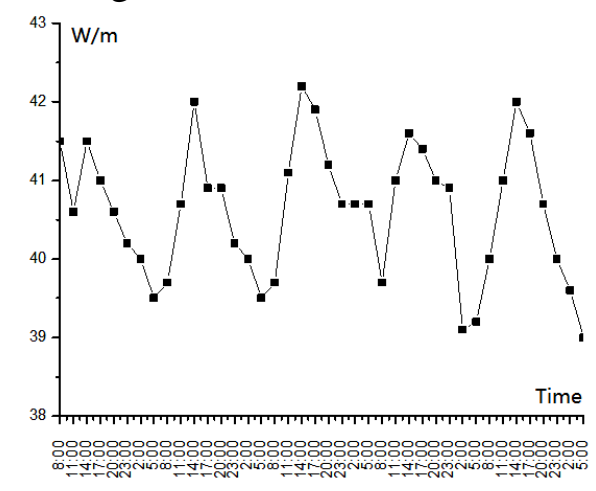

Figure 5 Heat transfer rate per unit depth

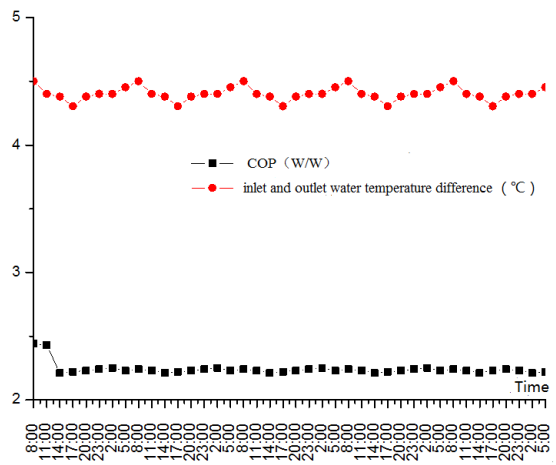

Figure 6 The COP and inlet and outlet water temperature variation in the system

It can be seen that the temperature of the inlet and the temperature difference of inlet and outlet of the buried tube tends to be stable with the system running. Heat transfer rate per unit depth in the fifth day reduced for $1.3 \mathrm{~W} / \mathrm{m}$ compared with the first day. During the period of test, the average quantity of heat transfer per unit depth is $40.2 \mathrm{~W} / \mathrm{m}$.

As shown in Fig. 6, the temperature difference of the system is about $4.5{ }^{\circ}$ Csteadily, the average COP of the system is 2.16 .

\section{The intermittent heat removal condition test}

Intermittent operation of the system was tested from December 30to January 5. System switched on in the day time and switched down in the evening. The system operated under the water velocity 
of $0.3 \mathrm{~m} / \mathrm{s}$, the time rate of start-up and shut-down of the system is $1: 2$, the results are shown in Fig. $7 \sim$ Fig. 10 .

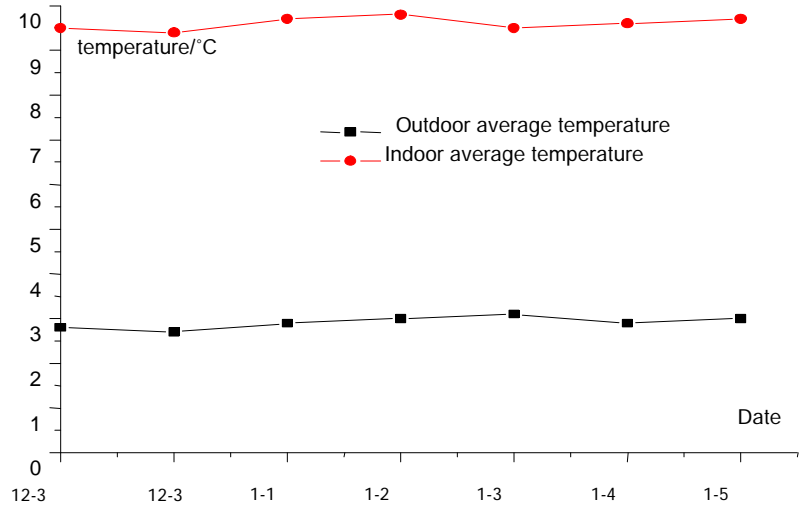

Figure 7 Indoor and outdoor temperature variation after $8 \mathrm{~h}$ running in the daytime

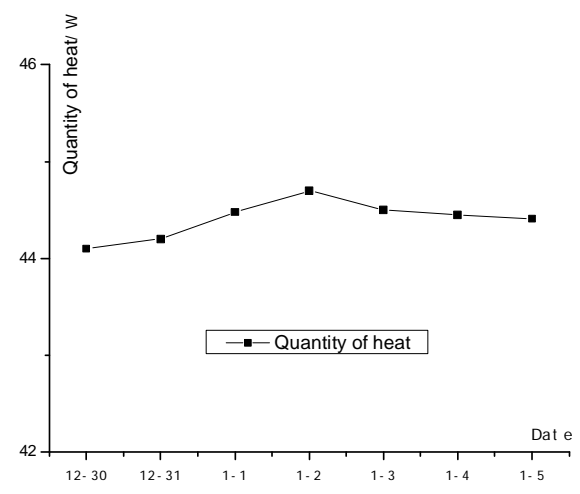

Figure 9 Quantity of heat exchange for unit holes depth after $8 \mathrm{~h}$ running in the daytime

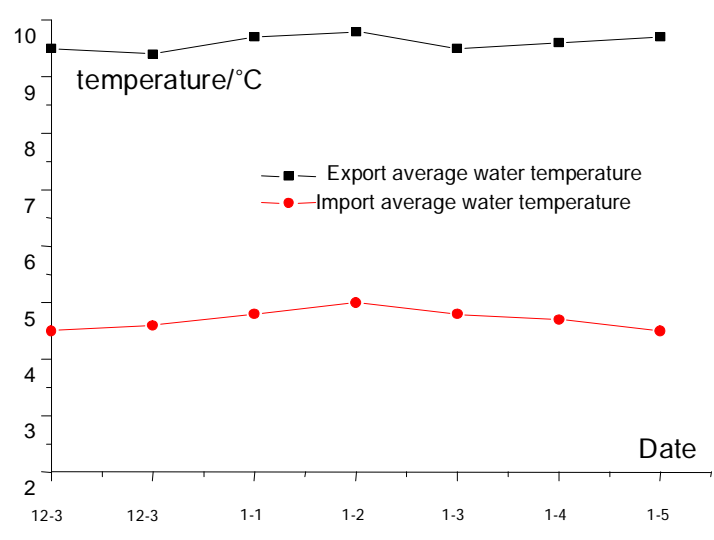

Figure 8 Import and export the change of average temperature of buried pipe after8 $\mathrm{h}$ running in the daytime

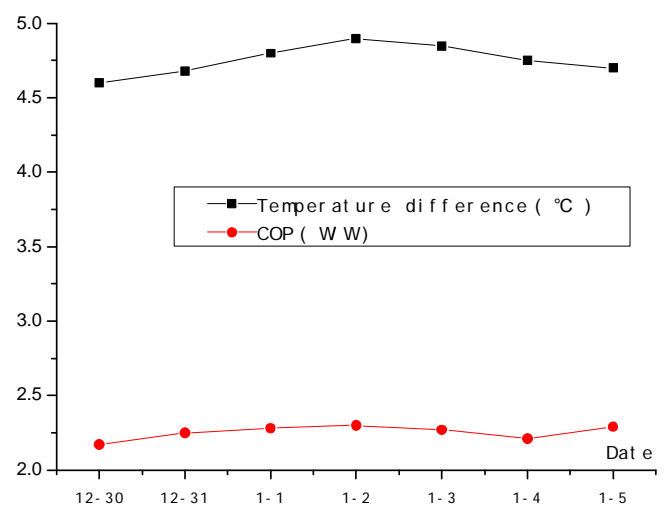

Figure 10 The system's COP and inlet and outlet water temperature difference after $8 \mathrm{~h}$ running in the daytime

It can be seen that quantity of heat transfer per unit depth and inlet water temperature of buried tube changes greatly under the test conditions. Average quantity of heat transfer per depth of one hole is $44.3 \mathrm{~W} / \mathrm{m}$, the COP of system is 2.3 on average.

\section{Operation simulation}

Although the mechanisms of heat transfer is the same, the condition of heat transfer between buried tube and the soil around is different in different seasons.

The key problem of ground source heat pump is the heat balance of soil ground in the system running after years. In this paper, the $\mathrm{k}-\varepsilon$ two-equation model was used to simulate the u-shaped tube fluid flow situation. Using three dimensional heat transfer model to simulate the surrounding soil temperature in system operation after a period of time. Simulation results are shown in Fig. 11 $\sim$ Fig. 14 . 


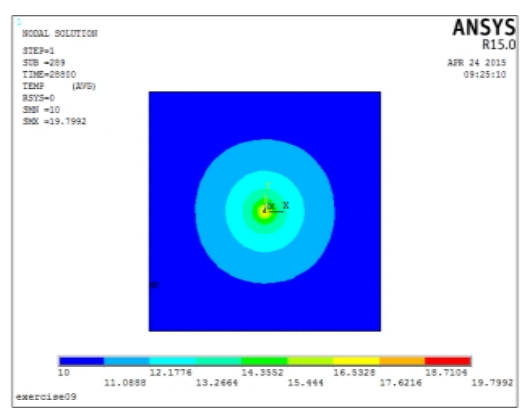

Figure 11 Temperature variation of the system running after $8 \mathrm{~h}$

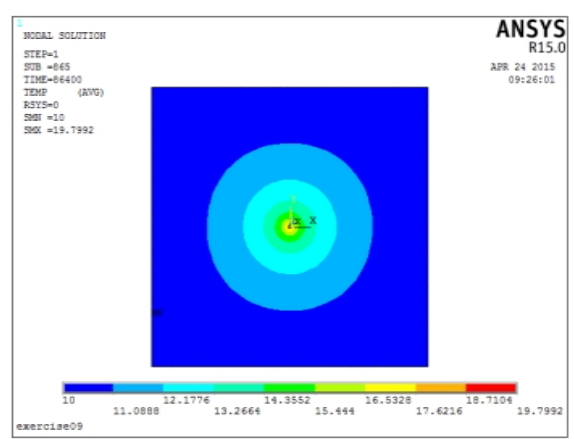

Figure 13 Temperature variation in the system running after $24 \mathrm{~h}$

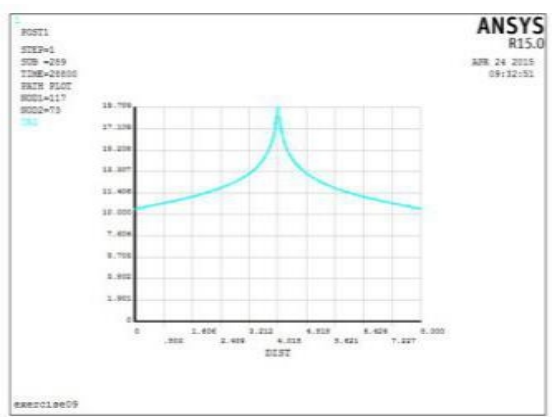

Figure 12 Temperature field distribution of center section at the time of 8 hours

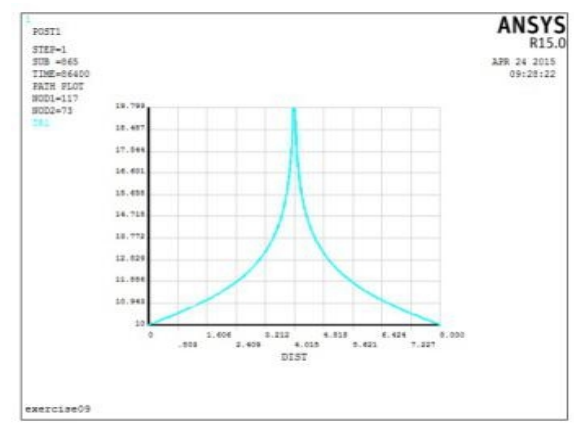

Figure 14 Temperature field distribution of center section at the time of 24 hours

After 8 hour running, the highest temperature of soil region is $19.8{ }^{\circ} \mathrm{C}$, the lowest temperature is the original temperature of $10{ }^{\circ} \mathrm{C}$.The influence area radius of single exchanger is about $1.4 \mathrm{~m}$. In the scope of the radius of $1.5 \mathrm{~m}$ to $2 \mathrm{~m}$, changes of temperature distribution are imperceptible, and it can be neglected. The temperature of the edge points is lower than the center of the model significantly in the group of Wells in the model. Change of internal temperature is more intense in the heat storage conditions. Although the temperature is higher than $15{ }^{\circ} \mathrm{C}$ in the point $0 \sim 0.5 \mathrm{~m}$ far from the edge, temperature of the edge is still $10{ }^{\circ} \mathrm{C}$. After 24 hour running, similar result can be gotten, the highest temperature of soil region is $19.8{ }^{\circ} \mathrm{C}$, the lowest temperature is the original temperature of $10{ }^{\circ} \mathrm{C}$. The influence of a single geothermal well radius is about $1.4 \mathrm{~m}$. Curve showing that the temperature is the highest at the center of the well.

\section{Conclusion}

In this paper, the performance of GSHP operated in the condition of continuous and intermittent under the typical climatic conditions in winter of Hefei was studied experimentally. Change and recovery of soil temperature field around the buried tube after $8 \mathrm{~h}$ and $24 \mathrm{~h}$ operation was simulated. It turned out that the operation parameters under the intermittent operation mode is better than continuous operation mode.GSHP had a good operation in winter generally.

\section{Acknowledgements}

This work was financially supported by the International Scientific and Technological Cooperation Program(No. 1503062012) and the Doctor Program of Anhui Jianzhu University (No. K10099). 


\section{References}

[1] Parham Eslami-Nejad, Mohamed Ouzzane, Zine Aidoun, A quasi-transient model of a transcritical carbon dioxide direct-expansion ground source heat pump for space and water heating, Thermal Engineering 91 (2015) 259-269.

[2] Bin $\mathrm{Hu}$, Yaoyu Li, Baojie Mu, Shaojie Wang, John E. Seem, Feng Cao, Extremum seeking control for efficient operation of hybrid ground source heat pump system, Renewable Energy 86 (2016) 332-346.

[3] A.C. Lyman, R.A. Stephan, K.A. Thole, L.W. Zang, S.B. Memory, Scaling of heat transfer coefficients along louvered fins, Exp. Therm. Fluid Sci. 26 (2002)547-563.

[4] Weijuan Sun, Pingfang Hu, Fei Lei, Na Zhu, Zhangning Jiang, Case study of performance evaluation of ground source heat pumpsystem based on ANN and ANFIS models, Thermal Engineering 87 (2015) 586-594.

[5] Amir A. Safa, Alan S. Fung, Rakesh Kumar, Heating and cooling performance characterisation of ground source heat pump system by testing and TRNSYS simulation, Renewable Energy 83 (2015) 565-575.

[6] Zhijian Liu, Wei Xu, Cheng Qian, Xi Chen, Guangya Jin, Investigation on the feasibility and performance of ground source heat pump (GSHP) in three cities in cold climate zone, China, Renewable Energy 84 (2015) 89-96.

[7] E. Pulat, S. Coskun, K. Unlu, N. Yamankaradeniz, Experimental study of horizontal ground source heat pump performance for mild climate in Turkey, Energy 34 (9) (2009) 1284-1295. 